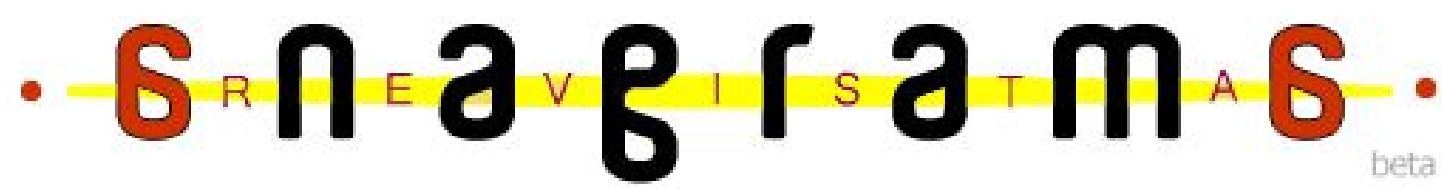

\section{Comportamento do Consumidor: análise das variáueis mais significativas no processo de compra da geração Y em São Paulo} Sasmin Porto Pereira da Silua ${ }^{7}$

\section{Resumo}

Como o universo e o comportamento de consumo do jovem paulista se configurou hoje é um tema cheio de possibilidades para as empresas em seus relacionamentos com esse grupo de consumidores. Dentro deste contexto, o objetivo deste artigo é investigar, entender e analisar as variáveis mais significativas que impulsionam o jovem da Geração Y a comprar roupas. Para isso, serão aplicadas diferentes metodologias, classificadas como exploratória e descritiva, em uma abordagem quanti-qualitativa, para responder a seguinte problemática: A Geração Y tem como característica ser multitarefa e utilizam a tecnologia para se comunicar. Esse fator pessoal impacta esta determinada Geração no processo de compra? Para esse trabalho delimita-se o objeto de pesquisa como os jovens residentes da cidade de São Paulo, entre 18 e 35 anos.

Palauras-chave: Comportamento do Consumidor; Geração Y; Compras; Roupas.

Introdução

O estudo do comportamento de compra do consumidor é muito complexo e acaba se tornando de grande importância para organizações empresariais, já que um dos principais conceitos do marketing diz que as empresas existem para satisfazer as necessidades dos consumidores (KOTLER, 2000), logo esta área desempenha papel

\footnotetext{
${ }^{1}$ Estudante de Graduação do $8^{\circ}$ semestre do curso de Marketing da Universidade Anhembi Morumbi (UAM). É bolsista de iniciação científica junto ao Programa Institucional de Bolsa de Iniciação Científica Anhembi Morumbi (PIBIC/AM), com o projeto de Comportamento do Consumidor: Análise das variáveis mais significativas no processo de compra da Geração Y em São Paulo, orientado pelo Prof. Dr. Sérgio Luis Ignácio de Oliveira.
} 
fundamental na busca do conhecimento da relação causal entre recursos aplicados nesta atividade e o consumo do bem ou serviço.

Segundo a consultoria DOM Partners, a Geração Y já é considerada como o maior segmento (volume de compras e quantidade de consumidores) em diversos setores da economia mundial. São tidos como a geração com maior propensão ao consumo e menor propensão à poupança. Segundo a ONU, citado no dossiê da DOM Partners, esse segmento da população representa cerca de $16 \%$ da população mundial. Esta é uma geração que começou a entrar no mercado de trabalho em 2005 e assim continuarão até 2018, portanto a tendência é que as empresas tenham cada vez mais integrantes desta geração. É tida por alguns como a geração na história, e em todo mundo, com o maior nível de escolaridade e formação. E com maior flexibilidade de conceitos e, portanto, menor nível relativo de preconceitos.

Em São Paulo, no censo realizado em 2010, foi identificado pelo IBGE (Instituto Brasileiro de Geografia e Estatística) a existência de mais 10 milhões de jovens entre 15 a 34 anos, isso representa 30\% da população total do Estado.

Este é um campo fértil de pesquisa, não só pela escassez de material de um tema tão contemporâneo, mas também porque é uma parcela da população que tem acesso a todo o tipo de informação de maneira rápida, segundo a DOM Partners, essa geração cresceu com disponibilidade tecnológica e acesso instantâneo a informações e foram os primeiros a adotar tecnologias como redes sociais, redefinindo a forma de pessoas se relacionarem entre si e com a tecnologia. São, portanto, o maior grupo de internautas da Web, Desta forma, seus hábitos de consumo e comportamento em geral influenciam e são influenciados diariamente.

A partir destas premissas, pergunta-se: A Geração Y tem como característica ser multitarefa e utilizam a tecnologia para se comunicar. Esse fator pessoal impacta esta determinada Geração no processo de compra?

Para responder a essa problemática, elencamos as seguintes hipóteses:

1. Sim, pelo fato da Geração Y ter como característica ser multitarefa e utilizar a tecnologia para se comunicar, enquanto fazem compras são capazes de se comunicar com seu círculo social e este fato impacta no processo de compra.

2. Não, mesmo com fato da Geração Y ter como característica ser multitarefa e utilizar a tecnologia para se comunicar, esse fator não os influencia no processo de compra. 


\section{Referencial teórico}

As duas principais funções do estudo do comportamento do consumidor, segundo Schiffman e Kanuk (2000) são: o entendimento do consumo como parte da vida dos indivíduos e a capacitação das empresas. Para Samara e Morsch (2005:2) o comportamento do consumidor é "o estudo que tem como objeto conhecer profundamente o comportamento das pessoas, suas necessidades, seus desejos e suas motivações, procurando entender o processo de como, quando e por que elas compram”. Sheth, Mittal e Newman (2001:29) definem comportamento do consumidor como "atividades físicas e mentais realizadas por clientes de bens de consumo e industriais que resultam em decisões e ações, como comprar e utilizar produtos e serviços".

Temos, portanto, teorias que concordam entre fatores como: o que, quando, como, por que, e com que frequência produtos e serviços são adquiridos e utilizados. A satisfação das necessidades e desejos dos consumidores como parte do estudo de ser comportamento ainda é ressaltada por Solomon (2002).

Com um objeto de estudo tão complexo quanto os indivíduos consumidores, o conhecimento de outras áreas é aplicado no estudo do comportamento de compra e consumo, áreas como psicologia e antropologia, de acordo com Samara e Morsch (2005).

Portanto, segundo (COBRA 1992), o consumo é largamente influenciado por inúmeros fatores como idade, grau de instrução, renda e gostos, entre outros. Desta maneira, ele se torna proeminente enquanto objeto de estudo, possibilitando a profissionais relacionados ao marketing agrupar os consumidores em grupos com similaridades relevantes, atuando em nichos com padrões homogêneos e com predisposições ao consumo parecidas.

Partindo da ideia da complexidade existente para entender o consumidor e o seu processo de compra, nesta parte do trabalho iremos analisar os principais, ou ao menos, aqueles mais importantes existentes no processo de compra. Assim, conforme Kotler e Keller (2006), o comportamento de compra do consumidor é influenciado por fatores culturais, sociais, pessoais e psicológicos, sendo que os culturais exercem a maior e mais profunda influencia.

Segundo Souza et al (2005), a cultura influencia profundamente o comportamento das pessoas, tendo em vista que se trata de valores surgidos a partir da infância, acompanhando a socialização do indivíduo, assim como a classe social onde se inserem. 
Kotler \& Kelly (2006) reforçam este pensamento quando afirmam que à medida que cresce, a criança absolve certos valores, percepções, preferências e comportamentos de sua família e de outras instituições.

Com um conceito mais modular e descritiva, Samara e Morsh (2007) afirmam que a cultura pode ser definida como a acumulação de valores, crenças, costumes, conhecimento, conceitos, preferências e gostos passados de uma geração para outra dentro de uma sociedade. Ao que se refere a subcultura, Kotler \& Kelly (2006) definem que este fator fornece a identificação e socialização mais específicas para seus membros. Entre subculturas estão as nacionalidades, as regiões, os grupos raciais e as regiões geográficas. Samara e Morsh (2007) ressaltam que subculturas são grupos, dentro de uma cultura, que exibem padrões de comportamento característicos o bastante para distingui-los dos outros, dentro da mesma cultura.

Souza et al (2005:17) ainda reforçam que:

Os profissionais de marketing criam produtos e serviços específicos para os grupos que têm suas subculturas acentuadas e, com isso, conseguem agradar os consumidores, principalmente os brasileiros, que, por terem um país tão rico em diversidade, podem encontrar produtos e serviços que se ajustem aos seus credos religiosos, a sua localização geográfica e ao seu estilo de vida, e ao seu status perante a sociedade.

Ainda dentro da lógica de Kotler \& Keller (2006) além dos fatores culturais, o comportamento do consumidor é influenciado por fatores sociais, como grupos de referência, família, papéis sociais e status.

Para se entender melhor os fatores sociais, é preciso entender o que são os grupos de referencias. Grupos de referencia, segundo Kotler \& Kelly (2006) são aqueles que exercem alguma influência direta (face a face) ou indireta sobre as atitudes ou comportamento de uma pessoa. Os grupos que exercem influencia direta são chamados grupos de afinidade. Dentro do grupo de afinidades, ainda temos os primários, como a família, amigos, colegas e vizinhos, portanto, pessoas com as quais se interage de forma continuam e informal.

Para Samara e Morsh (2007), o grupo de referência é o grupo do qual o indivíduo de identifica e serve como ponto de comparação - ou referencia - para formação geral ou especifica de valores, atitudes ou comportamentos, ditando-lhe um determinado padrão. 
Las Casas (2008) destaca que o grupo social que mais influencia na compra de produtos na sociedade é a família, pois a convivência familiar acaba contribuindo com regras e opiniões relativas à religião, economia, política e autoestima. Dessa forma, tais aspectos influenciam fortemente o comportamento de compra das pessoas.

Segundo Kotler \& Kelly (2006), as pessoas são significantemente influenciadas por seus grupos de referencia de pelo menos três maneiras distintas. Os grupos as expõem a novos comportamentos e estilos de vida. Além de influenciar suas atitudes e sua autoimagem, fazem pressões que podem afetar as escolhas reais de produto e marca. As pessoas também são influenciadas por grupos aos quais não pertencem: Grupos de aspiração são aqueles aos quais se espera pertencer, e grupos dissociação são aqueles cujos valores ou comportamentos são rejeitados. Para Solomon (2002) os grupos de referencia também influenciam os consumidores de três maneiras:

- Influência informativa: o indivíduo busca informação sobre o produto em grupos de profissionais especialistas ou associações que trabalham com produto como profissão.

Influência utilitária: a decisão de compra é baseada no desejo de satisfazer os colegas de trabalho ou pessoas com as quais o indivíduo tem interações

- Influência expressiva de valor: o indivíduo acha que a compra ou uso de determinada marca promoverá a imagem que os outros têm dele e lhe agregará a imagem que ele deseja ter ou aspira ser (senso de identidade e idealização).

Além dos fatores culturais e sociais, ainda temos os fatores pessoais. Ao longo da vida, todos os indivíduos passam por estágios pessoais diferentes, impactando diretamente na maneira que consomem, assim como afirmam Kotler \& Kelly (2006:179) “As pessoas compram diferentes artigos e serviços durante a vida. O gosto no que diz respeito a roupas, moveis e lazer em geral se relaciona a idade. Os padrões de consumo são moldados de acordo com o ciclo de vida da família e com o número, a idade e o sexo de seus membros em qualquer ponto no tempo." Ainda dentro do ponto de vista de Kotler \& Kelly (2006), outros elementos além de família e ciclo de vida serão influenciadores nos fatores pessoais, como a ocupação do indivíduo, sua situação econômica, seu estilo de vida, personalidade e autoimagem.

Solomon e Stuart (2000) afirmam o estilo de vida é representado por um conjunto de gostos que se expressam através de preferências das pessoas por esportes, interesses por 
música e opiniões sobre política e religião. Kotler e Keller (2006) ainda ressaltam estilo de vida representa a pessoa por inteiro, interagindo com seu ambiente.

Referindo-se à personalidade e autoimagem, Kotler e Keller (2006:181) observam que:

[...] Quando usamos o termo personalidade, queremos dizer traços psicológicos distintos que levam a reações relativamente coerentes e contínuas no ambiente. Em geral, a personalidade é normalmente descrita em termos de características como autoconfiança, domínio, autonomia, submissão, sociabilidade, resistência e adaptabilidade. A personalidade pode ser uma variável útil para se analisar as escolhas o comportamento do consumidor, uma vez que os tipos de marca do consumidor. [...] Muitas vezes, o consumidor escolhe e usa marcas com personalidade coerente com sua auto-imagem real (como essa pessoa se vê).

A partir disso, observa-se que os indivíduos possuem personalidades distintas e que estas provocarão estímulos diferenciados ao que se refere à decisão de compra. Portanto, as estratégias de marketing empresariais deverão desenvolver conteúdos de anúncios relacionados a estas diferentes personalidades de seus consumidores.

Como visto acima, além dos fatores já citados, existem os fatores psicológicos. Karsaklian (2000:20) sintetiza o processo que envolve os fatores psicológicos do consumidor:

\footnotetext{
$\mathrm{O}$ ato de compra não surge do nada. Seu ponto de partida é a motivação, que vai conduzir, a uma necessidade, a qual por sua vez despertará um desejo. Com base em tal desejo, surgem as preferências por determinadas formas especificas de atender a motivação inicial e essas preferências estarão diretamente relacionadas ao autoconceito: o consumidor tenderá a escolher um produto que corresponda ao conceito que ele tem ou que gostaria de ter de si mesmo.
}

Para Schiffman e Kanuk (2000), a motivação é a força motriz interna dos indivíduos que os impele à ação, a qual é produzida por um estado de tensão, que existe uma vez que há uma necessidade não satisfeita. Em complemento, Samara e Morsh (2007) defendem que a motivação é responsável pela intensidade, direção e persistência dos esforços de uma pessoa para alcançar determinada meta, assim a motivação é uma força variável e dinâmica que resulta da interação com a situação.

Além da motivação, dentro dos fatores psicológicos ainda teremos, segundo Kotler \& Kelly (2006) a percepção, aprendizagem e memória.

No caso da percepção, Solomon (2008:52) afirma que esta representa "o processo pelo qual sensações são selecionadas, organizadas e interpretadas". Em concordância temos Kotler \& Kelly (2006), que afirmam que a percepção é o processo por meio qual 
alguém seleciona, organiza e interpreta informações recebidas para criar uma imagem significativa do mundo. Logo, cada indivíduo interpretará o mundo a sua forma, o que será adequado para um não necessariamente será para outro. Ainda segundo Kotler \& Kelly (2006), no marketing, as percepções são mais importantes que a realidade, visto que é a percepção que de fato influencia o comportamento de compra do consumidor.

A aprendizagem segundo Kotler (2000) envolve mudanças no comportamento de uma pessoa surgidas da experiência, logo, a partir do momento que um individuo age devido a uma motivação, aprende. Em complemento, Solomon e Stuart (2000), afirmam que a aprendizagem é uma mudança causada pela informação ou experiência.

Para Kotler \& Kelly (2006), todas as informações e experiências acumuladas pelas pessoas ao longo da vida podem acabar armazenadas na memória de longo prazo dos indivíduos. Solomon (2011) deixa claro que para manter um relacionamento sólido entre cliente e marca é necessário fazer uma analogia entre aprendizado e memória, pois as organizações empresariais que aguçarem a memória de seus consumidores de várias maneiras, como propagandas que os façam lembrar de fatos que já haviam esquecido, irá fortalecer sua imagem e vínculo. Desta forma, este estímulo cognitivo será capaz de fazer com que a marca permaneça na memoria de seus consumidores por períodos maiores.

Para se entender melhor o processo de decisão de compra, podemos utilizar o modelo de 5 etapas desenvolvido pelos estudiosos de marketing por Kotler \& Kelly (2006). É importante lembrar que nem sempre os consumidores passam por estas cinco etapas para todas as suas compras, podem pular ou alterar a ordem em que elas estão classificadas. Estas são: Reconhecimento do problema, busca de informação, avaliação de alternativas, decisão de compra e comportamento pós-compra. Uma vez que o comportamento póscompra não está no escopo do presente trabalho, este conceito não será explanado.

Reconhecimento do problema: Segundo Blackwell, Miniard e Engel (2005:105), o reconhecimento da necessidade ocorre com a "percepção da diferença entre o estado desejado das coisas e o estado real, suficiente para estimular e ativar o processo de decisão". Portanto, quando o indivíduo já não está mais satisfeito com estado real ou quando o estado desejado aumenta, este reconhece uma necessidade que o impulsionará ao consumo. Em concordância com a visão de Blackwell et al, Kotler \& Keller (2006) afirmam que o reconhecimento do problema é quando o comprador reconhece uma necessidade: A necessidade pode ser provocada por estímulos internos ou externos. No primeiro caso, uma das necessidades normais da pessoa - fome, sede, sexo - sobe para o 
nível de consciência e torna-se um impulso. No segundo caso, em que a necessidade é provocada por estímulos externos, a pessoa admira algo, o que desencadeia a ideias sobre a possibilidade de fazer uma compra.

Busca de Informações: Solomon (2011) descreve que a busca de informações acontece de duas formas, interna e externamente. A busca por informação interna é realizada por meio de memórias guardas sobre muitos produtos já consumidos, mas geralmente a busca interna não é suficiente para a decisão de compra e necessita de um complemento, que é a chamada busca externa, estas poderão vir de amigos, mídia ou simplesmente através da observação das pessoas.

Para Kotler e Keller (2006) afirmam que a busca por informações pode ser separado em dois níveis: a busca moderada e a busca ativa de informações. A busca moderada é onde o consumidor está mais receptivo a informações sobre o produto, informações as quais ele já está exposto. No segundo nível, a pessoa embarca em uma busca ativa de informações, procura literatura a respeito o vasculha na internet e visita lojas para saber mais sobre o produto, ou seja, procura conhecer da melhor forma o produto que lhe interessa afim de escolher a melhor opção. Esta busca é de fato um processo muito decisivo para a efetivação da compra ou não, uma vez que o consumidor irá se munir com os atributos do produto de uma maneira mais simplória ou profunda.

Ainda seguindo Kotler \& Kelly (2006), é de grande interesse para o profissional de marketing são as principais fontes de informação a que o consumidor recorre e a relativa influência que cada uma exerce na decisão de compra. As fontes de informação do consumidor dividem-se e quatro grupos:

- $\quad$ Fontes pessoais: Família, amigos, vizinhos, conhecidos.

- Fontes comerciais: Propaganda, vendedores, representantes, embalagens, mostruários.

- Fontes públicas: Meios de comunicação de massa, organizações de classificação de consumo.

- Fontes experimentais: Manuseio, exame, uso do produto Marketing para atender esta demanda, o que é reflexo do mercado e das formas que as empresas conseguem se relacionar de forma adequada ao mercado.

As fontes que mais fornecem informações sobre o produto são as comerciais, no entanto, são as pessoais e as públicas as efetivas no processo decisório do consumidor, isso 
porque, são autoridades independentes e desempenham a função de avaliadoras das diversas opções de escolhas (KOTLER; KELLER, 2006).

Avaliação das Alternativas: É importante ressaltar que existem muitas formas pelas quais o consumidor irá avaliar suas alternativas, mas segundo Kotler \& Keller (2006), os modelos atuais tratam esse processo como cognitivamente orientado - isto é, consideram que o consumidor forma julgamentos principalmente em uma base racional e consciente.

Alguns conceitos básicos facilitam o entendimento do processo de avaliação do consumidor. Segundo Kotler \& Kelly o primeiro conceito é entender que o consumidor está tentando satisfazer uma necessidade. Segundo, está buscando certos benefícios na escolha do produto e terceiro, o consumidor vê cada produto como um conjunto de atributos com diferentes capacidades de entregar os benefícios para satisfazer aquela necessidade. Os atributos que interessam aos compradores variam de açodo com o produto. Os consumidores prestarão mais atenção aos atributos que fornecem os benefícios buscados.

Decisão de Compra: Segundo Kotler \& Kelly (2006), no estágio de avaliação, o consumidor cria preferências entre as marcas do conjunto de escolha e também forma uma intenção de comprar as marcas preferidas. Ao formar essa intenção de compra, ele pode passar por cinco subdecisões:

- Decisão por marca

- Decisão por revendedor

- $\quad$ Decisão por quantidade

- Decisão por ocasião

- $\quad$ Decisão por forma de pagamento

Kotler \& Kelly (2006) ainda afirmam que as compras de produtos para o dia-a-dia envolvem menos decisões e deliberações. Em alguns casos, os consumidores podem decidir não fazer uma avaliação formal de cada marca. Em outros, alguns fatores de interferência podem afetar a decisão final.

\section{Perfil da geração y}

Segundo Tulgan (2009), a Geração Y nasceu a partir de 1978, uma vez que esta é uma geração ainda recente, existem divergências e Tulgan, com sua definição, contempla 
outros autores. Normalmente a Geração Y são os filhos da Geração X e netos dos Baby boomers. Apesar de não haver um consenso sobre quando essa geração surgiu, alguns fatos podem ser levados em consideração, como a globalização e estabilidade economicamente. De acordo com Lipkin e Perrymore (2009), a forma de comunicação desta geração é completamente diferente de suas antecessoras, sendo a comunicação via mídia digital a língua nativa desta geração.

Para que se possa entender o contexto da Geração Y, é necessário explorar suas gerações antecessoras, a primeira delas foram os Baby boomers. Kupperschmidt (2000 apud Smola e Sutton 2002) afirma que este grupo recebeu o nome de Baby boomers pelo alto índice de nascimentos entre 1946 e 1964. Indivíduos estes que acompanharam as mudanças sociais e culturais das décadas de 60 e 70, sendo influenciados pela segunda guerra mundial e o movimento hippie. Em um artigo publicado pelo blog "Foco em Gerações", o coordenador do curso de Gestão de Recursos Humanos da Universidade Metodista de São Paulo, Rafael Chiuzi, alega que os Baby boomers são "pessoas que valorizam posições hierárquicas e tradições, além de prezarem pela durabilidade de relacionamentos interpessoais no trabalho, permeados por trocas mútuas e valores".

Se tivermos como premissa que grande parte dos Baby boomers são, em sua maioria, pais da Geração X, este valores foram repassados a seus filhos. A grande característica da Geração X para Smola e Sutton (2002), é que se desenvolveram em meio a grande diversidade, sólidas tradições e insegurança no âmbito financeiro, familiar e social. É uma geração tecnicamente competente e sente confortável em relação as diversidades, mudanças e competividade (KUPPERSCHMIDT, 2000 apud SMOLA e SUTTON, 2002). Ou seja, a insegurança familiar da Geração X afeta diretamente e Geração Y. Segundo Raines (2000, apud DINIZ, et al, 2011:5), esta geração foi gerada por mães independentes, tanto emocionalmente como financeiramente, com uma vida profissional ativa. Logo, seus filhos acabam sendo criados por profissionais, como as creches. O padrão de família é outro, não necessariamente representada pelos pais. A Geração Y foi criada para se prepara para o futuro, por isso, logo na infância já tinham muitos afazeres, como escola de idiomas e esportes. O tempo para "ser criança" foi esquecido.

Esta infância, muito diferente das outras gerações, desencadeou novos comportamentos. Na matéria publicada pela Revista Galileu, o professor Carlos Honorato da FIA afirma que "É a era dos indivíduos multitarefas", ou seja, na prática são indivíduos 
capazes de estudar, ler e utilizar as redes sociais ao mesmo tempo. Desta forma a noção de velocidade é outra, os resultados precisam ser mais rápidos, e os desafios, constantes.

Ainda na mesma reportagem feita pela Revista Galileu, a psicóloga Tânia Casado, coordenadora do Programa de Orientação de Carreiras (Procar) da Universidade de São Paulo, essa geração é como um “celular de última geração", ela afirma que "Eles já vieram equipados com a tecnologia wireless, conceito de mobilidade e capacidade de convergência. Usam uma linguagem veloz, fazem tudo ao mesmo tempo e vivem mudando de lugar."

O professor de comportamento humano da Fundação Dom Cabral, Anderson Sant'Anna, também citado na reportagem da revista Galileu, ainda completa este conceito quando afirma que "Tudo é possível para esses jovens. Eles querem dar sentido à vida, e rápido, enquanto fazem outras dez coisas ao mesmo tempo. Esses jovens estão aptos a desenvolver a auto-realização, algo que, até hoje, foi apenas um conceito. Questionando o que é a realização pessoal e profissional e buscando agir de acordo com seus próprios interesses, os jovens estão levando a sociedade a um novo estágio, que será muito diferente do que conhecemos."

O artigo da Revista Galileu ainda revela uma pesquisa da Fundação Instituto de Administração (FIA/USP) desenvolvido por Ana Costa, Miriam Korn e Carlos Honorato, foi realizada com cerca de 200 jovens de São Paulo revelou que 99\% dos nascidos entre 1980 e 1993 só se mantêm envolvidos em atividades que gostam, e 96\% acreditam que o objetivo do trabalho é a realização pessoal. Na questão "qual pessoa gostariam de ser?", a resposta "equilibrado entre vida profissional e pessoal" alcançou o topo, seguida de perto por "fazer o que gosta e dá prazer".

Logo, esta é uma geração que está em busca da auto-realização, muito diferente das gerações que a antecede. A "visão inflada sobre si mesmo", como ressalta o professor Harvey faz com os pertencentes a esta geração tenham grandes frustrações, uma vez que as suas expectativas foram completamente diferente da realidade.

\section{Análise dos dados}

A pesquisa exploratória foi idealizada com o objetivo de investigar uma parte do comportamento de compra e consumo da Geração Y. Realizada entre os dias 15 e 23 de 
Setembro de 2014, com 97 respondentes, do gênero feminino e masculino, moradores da cidade de São Paulo. A plataforma utilizada foi a Google Docs, disponível através de um link na internet. A pesquisa foi divulgada através de uma rede social.

As primeiras seis perguntas tinham como objetivo identificar aspectos demográficos dos respondentes, assim, dos 97 respondentes, $25 \%$ pertenciam ao gênero masculino e $75 \%$ ao feminino. Destaca-se que $72 \%$ ainda moram com os pais. Foi apontado que $49 \%$ moram na região Sul, $22 \%$ na região Leste, $14 \%$ na região Norte, $11 \%$ na região Oeste e a minoria de $4 \%$ no Centro da cidade de São Paulo. Em relação a escolaridade 67\% possuem Ensino Superior Incompleto, ,21\% tem Ensino Superior Completo, 8\% Ensino Fundamental Completo. As minorias Mestrado, Pós Graduação e MBA somam 4\% dos respondentes. Em relação a faixa etária, $60 \%$ tem de 20 à 25 anos, $29 \%$ tem de 18 à 20 anos, $6 \%$ tem de 25 à 30 anos e a minoria, 5\% tem de 30 à 35 anos. Em relação à classe social, $38 \%$ tem a renda de $2.040,00$ à $5.100,00,29 \%$ de $5.100,00$ à $10.200,00,19 \%$ acima de $10.200,00,11 \%$ de $1.020,00$ à $2.040,00$ e apenas $3 \%$ tem a renda familiar até $1.020,00$.

Após esse mapeamento sócio-demográfico, partimos para entender um pouco mais à respeito do consumido da geração Y. Para que pudéssemos entender o papel do consumo em seu cotidianos, perguntamos quantas vezes ao mês costuma comprar roupas. A grande maioria, $59 \%$, compra 1 vez a cada dois meses, $25 \%$ compra roupas uma vez ao mês, $10 \%$ 2 vezes ao mês e $6 \%$ compram roupas mais de uma vez por mês.

Com base na frequência de compra dos entrevistados, procuramos identificar a quantidade de roupa adquirida, com a pergunta "Em média, quantas peças de roupas você compra por vez?" $49 \%$ compram duas peças de roupas por vez, 24\% compram 3 peças, $11 \%$ compram apenas uma peça e também $11 \%$ compram mais de 4 peças. A minoria, com $8 \%$, compra 4 peças de roupas.

Depois procuramos entender os locais de compra com a pergunta "Quais locais/canais você utiliza para comprar roupas?" mapeia o principal canal utilizado pelos respondentes para comprar suas roupas. A grande maioria, 71\% compra suas roupas em Shoppings, $16 \%$ em lojas de rua, $10 \%$ pela internet e $3 \%$ compra roupas apenas no exterior.

A pergunta número dez "Suas compras são para uso" identificou qual segmento de roupas os respondentes compram. 50\% compram roupas para uso pessoal, ou seja, na vida 
social. 5\% compram para o uso profissional e $45 \%$ para uso tanto pessoal como profissional.

Como partimos do pressuposto que a geração Y esta interconectada nos meios digitais e consequentemente influencia e é influenciado pelo seu grupo de amigos, questionamos se "Você aceita/procura conselho dos seus amigos para comprar roupas?" $57 \%$ dos respondentes alegaram que, sim, aceitam/procuram conselho dos amigos para comprar roupas enquanto $43 \%$ não aceita/procura.

Também questionamos os respondentes em relação à forma de compra e pagamento de suas compras, com o objetivou apontar se os respondentes utilizam algum tipo de facilidade para o pagamento das roupas. $47 \%$ responderam que utilizam o cartão de crédito, $25 \%$ não usa nenhum tipo de facilidade, 23\% utiliza parcelamento, 3\% utiliza desconto à vista e $2 \%$ boletos.

Ainda com foco nas mídias sociais e a capacidade de interconectividade desse grupo, questionamos se os mesmo procuram fazer comparações pelos meios digitais em suas compras. $54 \%$ afirmou que não faz comparações e $46 \%$ faz comparações pelos meios digitais.

Com relação aos meios digitais perguntamos se costumam estar em contato com seus amigos através dos meios sociais ou compartilhar o que adquiriu. O nosso objetivo era apontar se os respondentes estão interagindo com seu círculo social no ato da compra. $67 \%$ não costuma estar em contato com os amigos, enquanto 33\% alegaram que sim.

Para saber se os mesmo costumam fazer comprar pontuais ou por impulso no qual objetivava expor uma parte do comportamento de compra dos respondentes, logo, se consideram que compram mais por uma necessidade ou por impulso. $61 \%$ compram de maneira pontual, por necessidade e $39 \%$ por impulso.

A última pergunta, perguntamos se independente do meio, se social ou profissional, o que você veste é compatível com sua identidade. Tinha como objetivo expor de que maneira os respondentes utilizam suas roupas. Se a vestimenta os representa ou não. A maioria esmagadora, 91\%, acredita que independe do meio, o que veste é compatível com a sua identidade, enquanto $9 \%$ acreditam que não.

\section{Considerações finais}

O presente trabalho tem por interesse entender as variáveis mais significativas no processo de compra e consumo da Geração Y residente da cidade de São Paulo. Dentro 
deste grande escopo de pesquisa, o objetivo foi responder a pergunta: A Geração Y tem como característica ser multitarefa e utilizam a tecnologia para se comunicar. Esse fator pessoal impacta esta determinada Geração no processo de compra?

Norteando a resposta a essa pergunta, apresentamos duas hipóteses:

1. Sim, pelo fato da Geração $Y$ ter como característica ser multitarefa e utilizar a tecnologia para se comunicar, enquanto fazem compras são capazes de se comunicar com seu círculo social e este fato impacta no processo de compra.

2. Não, mesmo com fato da Geração $Y$ ter como característica ser multitarefa e utilizar a tecnologia para se comunicar, esse fator não os influencia no processo de compra.

Após a análise da pesquisa exploratória, depreende-se que, mesmo que a Geração Y utilize muito redes sociais e ferramentas de comunicação ligadas a tecnologias, estes não são fatores que influenciam no processo de compra de roupas, uma vez que 54\% dos respondentes alegou que não faz comparações para comprar roupas, logo, a maioria não utiliza recursos tecnológicos no momento da compra, uma vez que $71 \%$ fazem suas compras em Shoppings. No que se refere à comunicação, 67\% declarou que não está contato com seus amigos através dos meios sociais ou compartilham o que adquiriram com seu meio social. Logo, a hipótese dois foi ratificada, enquanto a hipótese um foi refutada.

A partir do número expressivo de respondentes que alegaram que acreditam que o que veste é compatível com sua identidade, 91\%, e 50\% fazem compras para o uso pessoal, depreende-se que dentro da amostra e escopo deste trabalho que, a Geração Y busca, de fato, agir de acordo com seus próprios interesses, como declarou o professor de comportamento humano da Fundação Dom Cabral, Anderson Sant'Anna na reportagem publicada pela Revista Galileu. Este resultado também é embasado por Kotler e Keller (2006:181) quando se referem a auto-imagem: “[...] Muitas vezes, o consumidor escolhe e usa marcas com personalidade coerente com sua auto-imagem real (como essa pessoa se vê)".

É valido salientar que uma pesquisa mais ampla, com a realização de um maior número de entrevistas, poderia atingir resultados mais detalhados. 


\section{Referências Bibliográficas}

BLACKWELL, Roger D.; MINIARD, Paul W.; ENGEL, James F. Comportamento do consumidor. São Paulo: Pioneira Thomson Learning, 2005.

COBRA, Marcos. Administração de marketing. 2. ed. São Paulo: Atlas, 1992.

DOM PARTNERS. Dossiê $Y$ : Breve Manual de Compreensão da Geração $Y$. http://www.domsp.com.br/dossie-y-breve-manual-de-compreensao-da-geracao-y/. Acesso em 19/03/2014.

DINIZ, Cardoso Marcos Vinícius; DOS SANTOS Ferreira Cristiane; ARIENTE Marina; DOVIGO Aparecida Aline. "O processo evolutivo entre as gerações $X, Y$ e baby boomers”. In FEA USP: XIV Seminários em Administração, São Paulo. Outubro de 2011, pp. 5

FOCO EM GERAÇÕES. O, legado dos Baby Boomers. http://www.focoemgeracoes.com.br/index.php/2012/07/31/o-legado-dos-baby-boomers/. Acesso em 19/03/2014.

IBGE. INSTITUTO BRASILEIRO DE GEOGRAFIA E ESTATÍSTICA. http://www.ibge.gov.br/estadosat/temas.php?sigla=sp\&tema=sinopse_censodemog2010 .Acesso em 3/11/2013.

KARSAKLIAN, Eliane. Comportamento do consumidor. 2. ed. São Paulo: Atlas, 2004.

KOTLER, Philip. Administração de Marketing. São Paulo: 10. ed. Prentice Hall, 2000.

KOTLER, Philip; KELLER, Lane Kevin. Administração de Marketing. 12. ed. São Paulo: Prentice Hall, 2006. 
LAS CASAS, Alexandre Luzzi. Administração de Marketing: conceitos, planejamento e aplicações à realidade brasileira. São Paulo: Atlas, 2008.

LIPKIN, Nicole; PERRYMORE, April. A Geração Y no Trabalho: Como lidar com a Força de Trabalho que Influenciará Definitivamente a Cultura da Sua Empresa. Tradução: Bruno Alexander. Elsevier, 2009.

LOIOLA, Rita. Comportamento: Geração Y. Revista Galileu, edição 219/Outubro de 2009. http://revistagalileu.globo.com/Revista/Common/0,,EMI111370-17579,00GERACAO+Y.html. Acesso em 04/11/2013.

SAMARA, Beatriz Santos; MORSCH, Marco Aurélio Comportamento do consumidor: conceitos e casos. São Paulo: Pearson Prentice Hall, 2005.

SCHIFFMAN, Leon; KANUK, Leslie Lazar. Comportamento do consumidor.

Tradução: Vicente Ambrósio. 6. ed. Rio de Janeiro: LTC, 2000.

SHETH, Jagdish N.; MITTAL, Banvari; NEWMAN, Bruce I. Comportamento do Cliente: indo além do comportamento do consumidor. Editora Atlas. São Paulo: 2001.

SOLOMON, Michael R. O comportamento do consumidor: comprando, possuindo e sendo. 5. ed. Porto Alegre: Bookman, 2002.

SOLOMON, Michael R.; STUART, Elnora W. Marketing: real people, real choices. 2. ed. New Jersey: Prentice Hall, 2000.

SOUZA, Ana Rita Cruz; FARIAS, Juliana Maria Peres; NICOLUCI, Tânia Cristina. Principais Fatores que Influenciam os Consumidores Universitários a Frequentarem Bares Noturnos na Cidade de Presidente Prudente. http://intertemas.unitoledo.br/revista/index.php/Juridica/article/viewFile/367/361. Acesso em $04 / 08 / 2013$. 
SMOLA, Karen Wey; SUTTON, Charlotte D. Generational Differences: Revisiting Generational Work Values for the New Millennium. Journal of Organizational Behavior, v. 23, pp. 363-382, 2002.

TULGAN, Bruce. Not Everyone Gets a Trophy - How to Manage Generation Y. Estados Unidos : Jossey-Bass, 2009. 